\title{
A Study on Factors Influencing the Consumer Buying Behaviour Through Online Portal
}

\author{
Vinitha R S, Dr.Shanthakumari S S \\ (PhD Research Scholar, R\&D, Bharathiar University, Coimbatore,Professor, VIT Business School, VIT \\ University, Vellore)
}

\begin{abstract}
The use of internet for commercial purposes gave rise to the existence of the electronic commerce (ecommerce) phenomenon.Electronic commerce, also referred as e-commerce is defined by Oxford Dictionary (2012) as commercial transactions conducted electronically on the Internet'. People are doing business online and trade has become more easy and fast. Internet provides new ways to promote business. Website becomes the essence of online business as to show their services and products. The website structure is one of the main factors for an effective website services. Designers build a variety of websites according to their purpose. Consumers evaluate vendors before they enter into electronic exchanges and therefore, the characteristics of these vendors play an important role in facilitating an exchange. Online transactions can be considered as an activity in which the process of information retrieval, information transfer, and product purchase are taken place. The information retrieval and exchange steps are regarded as intentions to use a web site; however, product purchase is more applicable to an intention to handle a web-site.
\end{abstract}

Keywords:Electronic commerce, websites, website structure, online transactions

\section{Introduction}

The internet technology, appearing during the last quarter of the 20th century and having been used frequently for few years in daily lives, has influenced all parts of our lives in a short time. The change in technological area all over the world has changed the concept of information and communication. The use of internet for commercial purposes gave rise to the existence of the electronic commerce (e-commerce) phenomenon. With the implementation of these information and communication technologies by commercial institutions in order to support business activities, the electronic business concept was developed.

Electronic commerce, also referred as e-commerce is defined by Oxford Dictionary (2012) as commercial transactions conducted electronically on the Internet'. Another definition made by Financial Times (2012) as a buying and selling activity over the Internet. To sum up, e-commerce can be defined as the buying, selling and exchanging of goods and services through an electronic medium (the Internet) by businesses, consumers and other parties without any physical contact and exchange.

\section{Types of E-commerce}

Even-though innumerable companies now operate their business on the Internet some of the companies only have a web presence, called as click-only dot-coms, such as Amazon.com, Flipkart.com, Expedia.cometc,. These companies sell products and services directly to consumers via the Internet. On the other hand traditional companies also enhance their marketing strategies to adopt today's requirements and create their own online sales channels and become click-and-mortar companies. Nowadays it is hard to find an organisation that doesn't have a web presence (Kotler and Armstrong, 2012; 533). E-commerce has been divided into four categories considering the characteristics of the buying and selling parties. These categories are: business to business (B2B), business to consumer (B2C) or consumer to consumer (C2C) or consumer to business (C2B).

\section{Importance of E-Commerce (or) Online Shopping}

Internet makes life simple and innovative. People are doing business online and trade has become more easy and fast. Internet provides new ways to promote business. Website becomes the essence of online business as to show their services and products. Internet gathers all competitors and consumers in one place. It brings new lane to promote, advertise products and services in market (Barry Silverstein, 2002, p. 3). Total global Ecommerce sale in 2011 have grown to Euro 690 billion (USD 961 billion) and recorded an increase of $20 \%$ with an estimation of increase in the coming years and to cross the 1 trillion Euro mark in 2013. Asia pacific region is leading in terms of growth as compared to mature markets like US, UK, Japan and European countries. Asia Pacific recorded $130 \%$ growth,especially China in 2011. The online retailing is becoming an integral part of an economy and country and worldwide increasingly seeing trust and confidence in purchasing online. (AadWeening, 2012) "E-commerce is benefiting from several positive trends, including the continued rollout of broadband, increasing user comfort shopping online and the decline of certain brick-and-mortar retailers," 
(Imran Khan, 2011, P.416 ). Online consumers are always seeking new products, new attractiveness and the most important thing being price compatibility with their budget. The internet is the best way to save time and money through purchasing online within their range of budget at home or in anywhere. Online consumers don't have limits to online shopping.

\section{Online Shopping Motives and Internet adaption}

In general terms, motivations of consumers to engage in online shopping include both utilitarian and hedonic dimensions. According toHolbrook (1994), while some Internet shoppers can be described as 'problem solvers', others can be regarded as seeking 'fun, fantasy, arousal, sensory stimulation, and enjoyment'. The problem solvers merely shop online in order to acquire a specific product or service, in which case shopping is considered to be 'a task' or 'work' (Babin et al., 1994). The main concern of problem solvers is to purchase products in an efficient and timely manner to achieve their goals with a minimum of irritation. In contrast, other consumers may see online shopping as 'enjoyment' and seek the potential entertainment resulting from the fun and play arising from online shopping experience. They appreciate the online shopping experience for its own sake, apart from any other consequence such as an online purchase that may result (Holbrook, 1994). This dual characterization of consumers' motivations for online shopping is consistent with the framework adopted in this study where 'usefulness' and 'ease of use' reflect the utilitarian aspects of online shopping.

Adoption of online marketing which has been offered by manufacturers or serviceproviders is not easy. In fact adoption of online marketing is based on the rate of customer internet adoption instead of traditional channels which is mainly based oncustomer personal characteristics, website properties and service properties. It means that basic factors which affect on online marketing adoption will be the same as internet adoption and also e-commerce adoption which focuses on the customers' willingness to use internet instead of traditional channels in order to purchase aproduct, searching for information and using a service.

\section{Customer personal characteristics}

Sohn and Ahn (1999) showed that consumers' knowledge affects their adoption of ecommerce. Liang and Huang (1998) was of the opinion that customer's experience is an important factor in online purchasing. Kim and Kwon (1999) contended that a consumer whose lifestyle is more progressive and assertive in leisure activities use the internet more frequently and searches information through the internet more often. Limayem, Khalifaet al. (2003) added personal innovativeness as another personal characteristic in order to explain online shopping. Yang and Cho(1999)examined the impact of consumers' need for cognition, and search objectives on consumer information search through the internet.

\section{Designing the website}

It is an important issue for the marketer who wants to extent his/her activities in the field ofinternet marketing to distinguish the website design factors affecting the user. It has been said that the usability of the website can lead to the effectiveness of a website, the efficiency and satisfaction of the entire online action. The website structure is one of the main factors for an effective website services. Designers build a variety of websites according to their purpose. Some general observations about the structure of a website and their influence on consumers have been identified by many researchers.

Websites are fundamentally store houses of information that can help customers to search for information. Ranganathan and Ganapathy (2002) define the B2C website as a site that enables consumers to make purchases through the World Wide Web. According to Elliott and Speck (2005), the role and importance of retail websites may differ according to news sites, manufacturer sites and auction sites. The design characteristics of a web page may also have an impact on consumers' online buying decisions. Online retailers need to understand online consumers' characteristics to design an effective website.

Designing a website to satisfy customers' interests and needs is a key to the success of e-commerce. It is obviously necessary to adopt suitable strategies such as providing required photos or information to convince website visitors to buy online. Few organizations are aware of how to design websites to attract customers and to assist them with establishing better trading relations with their customers and enjoying more success in ecommerce.

\section{Merchant attributes/ Vendor Characteristics}

The "vendor" is defined as any seller who seeks commercial electronic exchange with an Internet user. This should not be confused with electronic service providers like Netcom or America Online who providecomputer time for a fee. A retailer with a home page on the $w w w$, like JC Penney, which provides users withthe opportunity to shop over the computer, is therefore classified as a vendor. Consumers evaluate thesevendors before they enter into electronic exchanges and therefore, the characteristics of these vendors play 
animportant role in facilitating an exchange. These vendors have to be superior to other vendors in alternative shopping modes in order to be noticed and contacted by consumers.

\section{E-Trust:}

E-Trust is a highly contextual construct; therefore, identifying itsantecedents for different environments is a challenging task. Various attempts have been made to uncover the factors determining consumer trust in Internet shopping, characteristics of trustworthy online transactions, and external manifestations of trust in offline environments that can be used to build trust in an online context. However, some studies still argue the importance of one-to-one interaction to build trust among transacting parties since general wisdom is that trust needs touch (Olson and Ol-son, 2000). Conflicting views about how to ensure and measure trust in an online context generates a valuable research area. Studies that develop scales or sub-constructs that can be used specifically to measure trust for web-based relationships and transactions would contribute greatly to the emarketing literature.

\section{External influence on online buying behavior}

Feather (2000) identified that those who use the internet more are likely to buy more products/services online, than those who use it less and providing logic of more usage of Internet might induce consumers to gain more exposure which might lead to more trust over Internet activities. This might be the earlier stage of exercising purchase behavior over Internet by collecting information as the consumer believed the reliability of the information available over Internet. Seckler (2000) observed that the consumers those who gained experience with online buying with a small purchase at the earlier stage will likely to develop confidence and skills that facilitate more ambitious purchase. It clearly shows that the more experience will install trust in consumers to buy expensive products over Internet.

\section{Subjective Norms}

A subjective norm is defined as "a person's perception of the social pressures put on him to perform or not perform the behavior in question" (Ajzen\&Fishbein, 1980). The online shopping is a voluntary individual behavior that can be elucidated by behavior theories such as the theory of reasoned action (TRA) introduced by Fishbein and Ajzen (1975) and the theory of planned behavior (TPB) proposed by Ajzen (1991). The TRA has been widely used by social psychologists and consumer behavior researchers. Choi and Geistfeld (2004) argue that a subjective norm consists of a normative belief that a reference group will approve or disapprove of a behavior and one's motivation to comply with the approval or disapproval of the reference group.

\section{Perceived benefit}

Perceived benefits are advantageous results derived from attributes. The benefits can be physiological, psychological, and sociological or material in nature (Gutman, 1982).Within the online shopping context, the consumers' perceived benefits are the sum of online shopping advantages or satisfactions that meet their needs or wants. There are many differences between a physical store and its electronic counterpart. Previous study found that internet shopping benefits was significantly associated with attitude toward online shopping and intentions to shop online.

\section{Perceived Risk}

Perceived risk was consumer's perceptions of the uncertainty, and advised consequences of buying a product orservice .Forsythe and Shi (2003) defined perceived risk in online shopping as the subjectively determined expectation of loss by an Internet shopper. Pavlou (2003) defined perceived risk as consumers' subjective fear of suffering a loss in pursuit of a desired outcome. Perceived risk is a consumer's belief about the potential uncertain negative outcomes from the online transaction (Kim et al., 2008). Perceived risk considered as the main barrier to online shopping.

\section{Conclusion}

Consumer online purchase intention was one of the intensive research areas in the extant literature. Consumer online purchase intention in the web-shopping environment will determine the strength of a consumer's intention to carry out a specified purchasing behavior via the Internet .Purchase intention can be classified as one of the components of consumer cognitive behavior on how an individual intends to buy a specific brand. Online transactions can be considered as an activity in which the process of information retrieval, information transfer, and product purchase are taken place. The information retrieval and exchange steps are regarded as intentions to use a web site; however, product purchase is more applicable to an intention to handle a web-site. Therefore, it is crucial to evaluate the concept of online purchase intention of the consumer through portal and the factors in this study will helpful to conduct the elaborative research on this subject. 


\section{References}

[1]. Arijit Banerjee (2013) to examine how much a consumer believes in Online Shopping. What particular factor influences the consumer to go on online purchase? International journal of management, engineering and

[2]. Chen, Y.-H., \& Barnes, S. (2007). Initial Trust and Online Buyer Behavior. Industrial Management \& Data Systems, 107(1), 21-36.

[3]. Suresh A. M \&Shashikala R (2011) Identifying Factors of Consumer Perceived Risk towards Online Shopping in India http://www.ipedr.com/vol12/61-C137.pdf.

[4]. Hausman, A. V., \&Siekpe, J. S. (2009). The effect of web interface features on consumer online purchase intentions. Journal of Business Research. doi:10.1016/j.jbusres.2008.01.018.

[5]. JayendraSinha\&Jiyeon Kim (2012) Factors affecting Indian consumer's online buying behaviour identified the factors affecting online shopping behaviour of Indian consumers.http://businessperspectives.org/journals_free/im/2012/im_en_2012_02_Sinha.pdf. 